\title{
Two approaches to discovering and developing new drugs for Chagas disease
}

\author{
JH McKerrow/ ${ }^{+}$, PS Doyle, JC Engel, LM Podust, SA Robertson, R Ferreira, T Saxton, M Arkin, \\ ID Kerr, LS Brinen, CS Craik
}

Sandler Center at Mission Bay, University of California, 1700 4th St. Mission, Bay Campus, 94158-2330

San Francisco, CA, USA

This review will focus on two general approaches carried out at the Sandler Center, University of California, San Francisco, to address the challenge of developing new drugs for the treatment of Chagas disease. The first approach is target-based drug discovery, and two specific targets, cytochrome P450 CYP51 and cruzain (aka cruzipain), are discussed. A "proof of concept" molecule, the vinyl sulfone inhibitor K777, is now a clinical candidate. The preclinical assessment compliance for filing as an Investigational New Drug with the United States Food and Drug Administration (FDA) is presented, and an outline of potential clinical trials is given. The second approach to identifying new drug leads is parasite phenotypic screens in culture. The development of an assay allowing high throughput screening of Trypanosoma cruzi amastigotes in skeletal muscle cells is presented. This screen has the advantage of not requiring specific strains of parasites, so it could be used with field isolates, drug resistant strains or laboratory strains. It is optimized for robotic liquid handling and has been validated through a screen of a library of FDA-approved drugs identifying 65 hits.

Key words: Chagas - T. cruzi - drug - protease inhibitor - CYP51 - HTS screen - amastigote

Chagas disease, caused by the protozoan parasite Trypanosoma cruzi, remains a major health problem due to inadequate therapy and lack of an effective vaccine. The two drugs currently used to treat Chagas disease, Nifurtimox (Nf) and Benznidazole (Bz), are chemically related nitrofurans and result in significant side effects. Bz may cause edema, fever, skin rash, articular and muscular pain, peripheral neuropathy and lymphadenopathy. More serious complications induced by $\mathrm{Bz}$ are agranulocytosis, initiated by neutropenia, sore throat, fever and septicemia; and thrombocytopenic purpura, characterized by reduction of platelets, petechiae, hemorrhagic blister and even mucosal bleeding (Coura \& de Castro 2002). Similarly, Nf may trigger weight loss, skin rash, psychosis, nausea and vomiting, leucopenia, neurotoxicity, peripheral neuropathy and tissue abnormalities (i.e., in adrenal glands, colon, esophagus, testicles, ovaries and mammary glands) (Coura \& de Castro 2002). Some controversy remains as to the effectiveness of current drug therapy in the chronic stage of Chagas disease and resistance to $\mathrm{Nf}$ has been documented. Chemotherapy for Chagas disease was traditionally recommended during the acute and indeterminate stages of infection however, recent reports of treatment of chronically infected

Financial support: NIH/NIAID P01 AI-035707, The Sandler Foundation

+ Corresponding author: jmck@cgl.ucsf.edu

Received 14 April 2009

Accepted 9 June 2009 patients have been reported to improve cardiac status (de Andrade et al. 1996, Sosa Estani et al. 1998, Estani 1999, Gallerano \& Sosa 2000, Jannin \& Villa 2007, Tanowitz et al. 2009). Retrospective studies in Latin America revealed that although both $\mathrm{Nf}$ and $\mathrm{Bz}$ present good activity during the treatment of acute and chronic recent infection cases, reaching an average index of parasitological cure around 60\%. In later chronic phase (patients with more than 10 years infection) parasitological cure is only obtained in $10-20 \%$ of the patients (Coura \& de Castro 2002). At present, even though the current agents have severe toxicities, treatment of chronic patients may be advisable as it often decreases clinical pathology (Coura \& de Castro 2002, Fabbro et al. 2007, Streiger et al. 2004, PS Doyle, unpublished observations).

It is clear that alternative drugs are desperately needed to treat Chagas disease. The WHO and their consultants have defined a target product profile for such new drugs which includes two key elements: (i) orally effective in the indeterminate and chronic stages of disease and (ii) a complete treatment regimen under 60 days. Considering that the current investigational treatment regimens for $\mathrm{Bz}$ and $\mathrm{Nf}$ are 60-120 days, 60 days would be a clear improvement over $\mathrm{Bz}$ or Nf. The recommended oral doses for the treatment of acute, congenital and chronic infections with less than 10 years of evolution are $8-10 \mathrm{mg} / \mathrm{Kg} /$ day $\mathrm{Nf}$ or $5-7.5 \mathrm{mg} / \mathrm{Kg}$ /day of $\mathrm{Bz}$, twice a day or three times a day. In the case of accidental infection, treatment must begin immediately and last for 10-15 consecutive days (1-9). Cases of late chronic infections without clinical manifestation or with mild cardiac or digestive manifestations should be treated for 60 to $\geq$ 90 days (Coura \& de Castro 2002). 
In this article we will outline the efforts of the Sandler Center at the Mission Bay Campus (QB3) of the University of California, San Francisco, to address the need for new drugs targeting T. cruzi. Several other centers, public-private partnerships, and the WHO itself are also working on this unmet medical need (Table I). It is hoped the confluence of these efforts will yield new directions of research and drug development that are synergistic. For example, it is envisioned that the ideal therapy for Chagas disease may involve a drug combination to both enhance efficacy against acute or chronic infection and to also minimize the risk of drug resistance. Any improvements in the toxicity profile of therapy would be welcomed by the community. The more leads/approaches from different sources that progress to investigational drug candidates, the better chance that new treatments for this often fatal infection will be available to patients in the near future.

\section{The first approach: target-based drug discovery and development targeting cytochrome P450 CYP51 (sterol 14alpha-demethylase) inhibitors}

T. cruzi is an intracellular parasite that relies on biosynthesis of endogenous sterols for viability and proliferation and is susceptible to ergosterol biosynthesis inhibitors in vitro (Urbina 1999a, b, Buckner et al. 2003). But commercially available ergosterol biosynthesis inhibitors (ketoconazole, fluconazole or itraconazole), which are highly successful in treating fungal diseases, fail to eradicate $T$. cruzi from experimental animal models and human patients. Only in a fourth generation of azole antifungal agents, such as D0870 and posaconazole, has remarkable in vivo anti-T. cruzi activity been demonstrated (Urbina 2001). The effectiveness of these drugs in eradicating intracellular parasites, stems from their pharmacokinetic properties, including long half-lives and large volumes of distribution. Although these newer anti-fungal agents promise practical and economic benefits for treatment of Chagas disease, there are substantial differences between fungal and protozoan CYP51 enzymes. Rational tuning of the inhibitors to fit specific CYP51 isoforms would improve the efficacy and selectivity of potential drugs. Selectivity of sterol $14 \alpha$-demethylase inhibitors to prevent host/pathogen cross-reactivity is pharmacologically important, as CYP51 is also present in humans.

In earlier work, we used a soluble bacterial CYP51 orthologue from Mycobacterium tuberculosis as a target in library screens of synthetic organic molecules to identify chemical scaffolds capable of conforming to a portion of the active site that is conserved across the CYP51 family (Podust et al. 2007). An appropriate scaffold was identified with this methodology and this scaffold was used in a second generation of compounds to deliver arbitrary chemical groups into the CYP51 active site (Chen et al. 2009). X-ray structure analysis confirmed the binding modes for three second-generation CYP51 inhibitors. The generation of both T. cruzi and Trypanosoma brucei recombinant CYP51 enzyme has enabled spectroscopic binding studies of inhibitors with
TABLE I

Efforts directed at discovery and development of drugs for Chagas disease

DNDi (multiple partners)

Federal University of Alagoas, Brazil

Federal University of Minas Gerais, Brazil

Federal University of Pernambuco, Brazil

Federal University of Rio de Janeiro, Brazil

FIOCRUZ, Brazil

Instituto de Parasitología y Biomedicina López-Neyra, Spain Instituto Militar de Engenharia, Brazil

Instituto Nacional de Parasitología Dr. Mario Fatala Chabén, Argentina

Instituto Venezolano de Investigaciones Cientificas, Venezuela

Sandler Center, Mission Bay, United States

Universidad Autónoma de Yucatán, Mexico

Universidad de Buenos Aires, Argentina

Universidad de la Republica, Uruguay

Universidad Nacional de Córdoba, Argentina

Universidad Nacional de Rosario, Argentina

University of Chile, Chile

University of Cincinnati, United States

University of Dundee, United Kingdom

University of São Paulo, Brazil

University of Washington, United States

WHO (multiple partners)

these proteins in parallel with studies on CYP51 from $M$. tuberculosis. These studies have revealed that one of the second generation compounds, $\alpha$-[[(4-methylcyclohexyl) carbonyl]amino]-N-4-pyridinyl-1H-indole-3-propanamide (ChemDiv ID\# C155-0123), has a nanomolar binding affinity towards CYP51 of T. cruzi and no binding towards the $T$. brucei orthologue. C155-0123 has potent, selective anti-T. cruzi activity, and was shown to cure mouse macrophages infected with $T$. cruzi $\mathrm{Y}$ strain at 10 micromolar concentrations without harming the host macrophage cells. C155-0123 is currently being evaluated in animal models of Chagas disease.

Although C155-0123 failed to co-crystallize with the M. tuberculosis CYP51, a collection of co-crystal structures obtained with structurally related second generation compounds and M. tuberculosis CYP51 supported the assumption that the C155-0123 binds to the T. cruzi CYP51 enzyme via the indole ring of the inhibitor. The indole ring thus takes the place of the phenylalanine 78 found in the M. tuberculosis CYP51 enzyme which is isoleucine 105 in the T. cruzi CYP51 (Podust et al. 2004). A residue at this position determines the substrate specificity of CYP51 towards sterols that are mono- or dimethylated at the C-4 atom (Lepesheva et al. 2006). Isoleucine 105 of $T$. cruzi CYP51 is unique among the residues occupying this position, as all other parasitic protozoa and plants have phenylalanine, whereas in hu- 
mans and animals it is leucine. Collectively, the accumulated data demonstrate striking sensitivity of CYP51 to the alteration of the topography of its active site at this position. This is one of the advantages we intend to exploit in the rational design of species-specific sterol 14 alpha-demethylase inhibitors, building upon the structural knowledge already obtained for the bacterial CYP51 orthologue (Podust et al. 2001a, 2007, Eddine et al. 2008, Chen et al. 2009) and the current efforts to determine the X-ray structure of T. cruzi CYP51.

\section{Protease inhibitors targeting cruzain (aka cruzipain)}

Proteases are druggable targets and protease inhibitors have proven to be effective drugs for diabetes, osteoporosis, certain cancers and infectious diseases (Renslo \& McKerrow 2006, Gauthier et al. 2008). The major protease of $T$. cruzi is cruzain (aka cruzipain). This protease is expressed in all stages of the T. cruzi lifecycle, but is localized to different compartments. In the epimastigote stage, the protease is confined to the lysosome (reservosome) in the posterior portion of the cell. While its exact function is not known, it is likely involved in degradation of proteins scavenged from the blood meal of the insect vector. In support of this hypothesis is the fact that homologous proteases from Plasmodium falciparum and Schistosoma mansoni function in hemoglobin degradation (Rosenthal et al. 2002, Delcroix et al. 2006).

In the intracellular amastigote stage, the principal stage for drug targeting, the protease appears in two locations. While some protease can still be detected in the lysosome-related compartment much of cruzain is on the surface of the parasite, directly in contact with host cell cytoplasm (Souto-Padron et al. 1990, Engel et al. 2000, Vieira et al. 2005, PS Doyle, unpublished observations). Thus the protease may operate in two chemical microenvironments - at $\mathrm{pH} 5.5$ within the lysosome and at neutral $\mathrm{pH} 7.4$ when expressed on the surface of the amastigote in the host cell cytoplasm. This is important for protease inhibitors, which may have a $\mathrm{pH}$-dependent alteration in structure (e.g., protonation vs. non-protonation). A notable example is the compound WRR-483, an analog of the parent vinyl sulfone K777 (aka K11777), which contains a protonizable arginine side-chain. This inhibitor showed unexpected activity against the parasite in culture and in an animal model of disease. This may be due to entry through the plasma membrane into the host cell cytoplasm of the non-protonated form, which is subsequently protonated within the parasite. The protonated form is a better cruzain inhibitor.

Cruzain has excellent pre-clinical validation evidence as a viable drug target. Multiple protease inhibitors of different scaffolds and catalytic mechanisms show activity against parasites in culture and in animal models of disease (Engel et al. 1998a, Du et al. 2002, Greenbaum et al. 2004, Fujii et al. 2005, Caffrey et al. 2007, Brak et al. 2008, Fricker et al. 2008, McKerrow et al. 2008). While gene knockout of cruzain was not achieved (presumably due to lethality), over-expression of cruzain in the parasite led to enhanced metacyclogenesis (Tomás et al. 1997). More importantly, a parasite clone expressing $<1 \%$ of wildtype protease activity was not able to establish infection in wildtype mice, but could establish infection in severely immunodeficient RAG 1 knock out mice (our unpublished observations). This implied a role for cruzain in parasitic immune evasion. Evidence has now been accumulated that cruzain may degrade NFKappa B as a means of arresting the immune response during the early stages of infection when parasites enter host macrophages (PS Doyle, unpublished observations). This lack of activation of infected inflammatory cells at the insect bite site would provide a means by which the parasites could egress from this location within macrophages and disseminate to other tissues. In support of this hypothesis, infection of immune deficient (RAG 1) knock out mice with wild type $T$. cruzi resulted in widespread infection of macrophages, including Kupffer cells of the liver and macrophages in the spleen (Doyle et al. 2007). This immunodeficient mouse model also reflects the widespread and often fatal occurrence of Chagas disease in AIDS and immunosuppressed patients who have concurrent $T$. cruzi infection.

In addition to its role in immune evasion, and possibly in facilitating metacyclogenesis, inhibition of cruzain activity in the parasite leads to parasite death in vitro due to accumulation of a toxic precursor within the Golgi (Engel et al. 1998a, b). This mechanism of drug action reflects the autocatalytic activation of cruzain in or shortly after transit through the Golgi of the parasite. In the absence of protease activity, the prodomain remains attached to the catalytic domain of cruzain and unprocessed cruzain bound to the protease inhibitor is retained within the Golgi compartment. This protein accumulation in turn leads to osmotic shock of the Golgi and, ultimately, the entire endoplasmic reticulum of the parasite. Although difficult to achieve, parasites resistant to this mechanism were ultimately isolated and became resistant through increased secretion of the precursor cruzain zymogen into the extracellular space (Engel et al. 2000). However, the decrease of precursor protein required to circumvent the toxic effect of the cysteine protease inhibitor led to significantly diminished cruzain activity within the parasite and the inability of $T$. cruzi to establish viable infections in animal models of disease (unpublished observations).

\section{Cruzain inhibitor K777 as a clinical candidate}

K777, a vinyl sulfone protease inhibitor of cruzain, was effective in curing or alleviating $T$. cruzi infection in preclinical proof-of-concept studies and has now entered formal preclinical drug development investigations. Studies of K777 have proven that the targeting of cruzain can be done selectively and effectively enough to cure $T$. cruzi in acute and non-acute models of infection in mice and also ameliorate cardiac damage in dogs. We have now documented the efficacy of K777 against various T. cruzi strains (e.g., Y, Tulahuén, CL, CA-I/72, PSD-1 and PSD-2 isolates), that represent a spectrum of T. cruzi $i$ ith various tissue tropisms, and even against $\mathrm{Nf}$ and Bz-resistant T. cruzi (Table II) (Nozaki et al. 1996, PS Doyle, unpublished observations). Importantly, K777 also produced an additive effect on parasite killing when used in combination with Bz (Table III). 
The activity of K777 versus multiple $T$. cruzi strains is important because T. cruzi in the field comprises numerous clonal populations with diverse characteristics, including sensitivity or resistance to $\mathrm{Nf}$ and $\mathrm{Bz}$, diverse biological parameters (e.g., growth rate, infectivity and pathogenicity) and enzymatic differences (Doyle et al. 1984, Dvorak 1984, Kirchhoff et al. 1984, Postan et al. 1984, 1987, Engel et al. 1985, 1990, Nozaki \& Dvorak 1993, Ratier et al. 2008). This heterogeneity of T. cruzi strains influences the clinical manifestations of Chagas disease (Dvorak 1984, Andrade et al. 1999).

Multiple studies in mouse models of acute Chagas disease have indicated that inhibition of cruzain by inhibitors such as K777 can cure infection with treatment regimens of 20-30 days (Engel et al. 1998a, Doyle et al. 2007, PS Doyle, unpublished observations). In a study of $T$. cruzi infection in the dog, oral administration of K777 for 14 days at $50 \mathrm{mg} / \mathrm{kg}$ twice daily was sufficient to protect against cardiac damage, as assessed by histopathology and troponin I levels (Barr et al. 2005). Using allometric scaling to estimate the human equivalent dose from Chagas infected mouse model studies, it is predicted that an oral dose of approximately $10 \mathrm{mg} / \mathrm{kg}$ for 14-30 days may be an effective therapeutic regimen for Chagas disease intervention with this protease inhibitor. If so, it not only meets but also exceeds the criteria set up by the WHO for the target product profile of Chagas disease treatment. K777 has undergone rodent, dog and primate testing, including a 14 day GLP chronic dosing toxicity study in rats. The maximum tolerated dose was determined in this study to be in excess of $150 \mathrm{mg} / \mathrm{kg} /$ day, and the no adverse effect level (NOAEL) dose to be approximately $50 \mathrm{mg} / \mathrm{kg} / \mathrm{day}$ (SRI International study, sponsored by NIAID, NIH).

Any discussion about the drug development progress of K777 should address the statement on the Institute for One World Health's (iOWH) website that development of K777 by iOWH found was halted in 2005 due to "hepatotoxicity and manufacturing problems". Elevation of alanine aminotransferase (ALT), a biomarker of reversible hepatocyte injury, is interpreted as "hepatoxicity". In the original SRI preclinical studies, ALT elevations were seen at doses of $200 \mathrm{mg} / \mathrm{Kg}$ in monkeys and $100 \mathrm{mg} / \mathrm{Kg}$ in dogs over a 7-day period. The proposed therapeutic dose adjusted to monkeys or dogs would be $50 \mathrm{mg} / \mathrm{Kg}$ and less than $10 \mathrm{mg} / \mathrm{Kg}$ for the equivalent human dose.

Since 2005, a number of more stringent follow-up safety studies were performed under contract from the NIAID. NIAID has now assumed management of K777 development following release of intellectual property from iOWH. A 7-day and 14-day chronic per orem (p.o.) dosing study in rodents performed by SRI International confirmed that ALT elevation occurs only at doses at or above $150 \mathrm{mg} / \mathrm{Kg}$. Even at $300 \mathrm{mg} / \mathrm{Kg}$ the ALT elevation, and any histological changes in the liver, were reversible following cessation of therapy. As noted above, the NOAEL for K777 will likely lie between $50-100 \mathrm{mg} / \mathrm{Kg}$ p.o. It should also be noted that many currently used drugs, including widely used cholesterol-lowering drugs and acne medications, result in elevated ALT levels that are reversible. A noteworthy study funded by iOWH itself
TABLE II

Effect of K11777 in vitro

\begin{tabular}{lccc}
\hline \multirow{2}{*}{$\begin{array}{l}\text { K11777 } \\
\text { concentration }\end{array}$} & $\begin{array}{c}\text { Trypanosoma cruzi } \\
\text { Independent } \\
\text { experiments }\end{array}$ & \\
& strain & $\mathrm{n}$ & Outcome \\
\hline \multirow{4}{*}{$10 \mu \mathrm{M}$} & $\mathrm{Y}$ & 42 & CIC \\
$(27$ days $)$ & $\mathrm{CA}-\mathrm{I} / 72$ & 5 & CIC \\
& $\mathrm{CL}$ & 1 & CIC \\
& PSD1 $^{b}$ & 2 & CIC \\
& PSD2 $^{b}$ & 1 & CIC \\
\hline
\end{tabular}

$a$ : irradiated $\mathrm{J} 774$ macrophages were infected with the appropriate $T$. cruzi strain and treated with $10 \mu \mathrm{M}$ K11777 in RPMI medium for 27 days. Cultures were then maintained in medium without the inhibitor for up to 42 days to confirm cure of the infected macrophages. Each independent experiment was performed in triplicate $(\mathrm{n}=3) ; b$ : Benznidazole and/or Nifurtimox resistant strains isolated from chagasic patients; CIC: cured infected cells.

\section{TABLE III}

Additive effect of K11777 and Benznidazole ${ }^{a}$ on the survival (days) of Trypanosoma cruzi-infected muscle cells in vitro

\begin{tabular}{lccccc}
\hline Treatment & 0 & $0.1 \mu \mathrm{M}$ & $0.5 \mu \mathrm{M}$ & $1 \mu \mathrm{M}$ & $5 \mu \mathrm{M}$ \\
\hline None (control) & 5 days $^{b}$ & & & & \\
Benznidazole & & ND & 5 days & 5 days & 27 days \\
K11777 & ND & $5-7$ days & $7-9$ days & 37 days \\
Benz+K11777 & & 5 days & $5-7$ days & $7-9$ days & $\geq 47$ days $^{c}$ \\
\hline
\end{tabular}

$a$ : treatment duration 27 days; $b$ : host cell monolayer destroyed; $c$ : experiment ended with host cells cured. Neither intracellular amastigotes nor free trypomastigotes were observed; ND: not done. See Doyle et al. (2007) for details of culture assay. Host cell monolayer is destroyed by parasite replication and ruptures in 52 days in absence of drugs.

showed that, in vitro, human hepatocytes were much less susceptible to high concentrations of K777 than monkey, rodent or dog hepatocytes. In fact, no toxicity to human hepatocytes in culture was seen even at concentrations of K777 up to 100 micromoles. Therapeutic blood levels that lead to cures in mouse models of Chagas disease are in the range of 0.5-5.0 micromoles.

As to manufacturing issues, scale-up since 2005, under NIAID contract, has revealed no problems and funding is currently being sought for manufacture of $2 \mathrm{Kg}$ of Good Manufacturing Practices (GMP) K777 for Phase I dose escalation studies in healthy human volunteers.

A non-rodent 28-day GLP toxicity study and safety pharmacology assessments (CNS, cardiovascular and pulmonary) for K777 are currently being planned. Scale up of K777 for GMP manufacture of drug substance and 
drug product for use in the clinic will be conducted. Assuming no new safety signals are uncovered in the remaining studies required to complete an Investigational New Drug (IND) application, it is anticipated that an IND package for K777 will be submitted to the Food and Drug Administration (FDA).

It is currently proposed to conduct the initial First Time in Man Phase 1 dose escalation clinical trial to assess safety, tolerability and pharmacokinetics after a single oral dose in the United States in healthy patient volunteers. If the Phase 1a clinical trial shows K777 to be safe and well tolerated, we would look to partner the program with an international organization for further clinical development.

There are several potential designs to the next phase of clinical assessments; one possibility is to run a combination Phase $1 \mathrm{~b} /$ Phase $2 \mathrm{a}$ clinical trial in a Chagas patient population to assess multi-dose safety and pharmacokinetics. This would allow direct assessment of the most effective dosing regimen early in the drug development program. The acute patient population is likely the most practical group to consider for attaining proof-of-concept in the Phase 2a (or Phase 1b/2a) setting due to the rapid and easy assessment of patient improvement as determined by parasite load in blood. However, sites in Argentina where acute patients can be identified would be required for this type of clinical investigation to be successful. Alternatively indeterminate-stage patients may be studied in Phase 2a if appropriate biomarkers are available to allow assessment of response to therapy in a short timeframe. Phase $2 \mathrm{~b}$ and Phase 3 clinical trials could be open for all stages of the disease or multiple cohorts reflecting different patient populations could be assessed in parallel so that the best timing of the delivery of treatment to patients could be identified. A combination arm in some late stage studies with $\mathrm{Bz}$ will be an important consideration, as the effect of the combination of the two drugs has been shown to be additive against parasite infection in cell culture (Table III). This suggests that it may be possible to reduce the dose of $\mathrm{Bz}$ in combination therapy and therefore reduce the incidence of side effects of the drug. It is also becoming clear that multi-drug therapy can prevent or significantly delay the onset of resistance to either component. One potential hurdle in Phase 3 clinical trials in Chagas, especially if the trial includes intermediate and chronic stage populations, is that mortality may be a required endpoint, making the length of the trial very long. Discussions with the FDA and WHO to define surrogate markers for rapid endpoint assessments of treatment success will be important in ensuring new, more effective and safer drugs get to market quickly for this underserved Chagas patient population. Assessment of long-term survival/cure of the infection would then follow as population/Phase 4 studies once the new treatment is made available to the patients in need of a broader choice of treatments for Chagas infection.

Other approaches to cruzain protease inhibitors Several classes of cruzain inhibitors have been previously discovered or synthesized, most of which are covalent inhibitors (Du et al. 2002, Greenbaum et al. 2004, Fujii et al. 2005, Brak et al. 2008, Chen et al. 2008, Jaishankar et al. 2008). In an effort to discover new inhibitor scaffolds, we have used molecular docking to screen commercially available molecules from several public-access libraries, including ZINC (http://zinc.docking.org).

We have selected several top-ranking molecules for experimental testing, which is now ongoing. An NMR structure of cruzain has also been generated to facilitate analysis of DOCK hits, and also allow experimental testing of new competitive inhibitors.

\section{The second approach to identifying drug leads: whole parasite phenotypic screens}

To facilitate the rapid screening of large drug-like libraries, we have recently developed and validated an image-based High Throughput Screening (HTS) assay for the pathogenic amastigote stage of $T$. cruzi. Our assay can be used with a variety of $T$. cruzi isolates and host cells and simultaneously measure trypanocidal efficacy and drug cytotoxicity versus the mammalian host cell. We can use parasites strains with different biological characteristics (e.g., resistant to $\mathrm{Nf} / \mathrm{Bz}$, field isolates, clinical strains) and a range of host cells from primary human cell cultures to established cell lines. In this screen, an effective compound significantly decreases the number of intracellular parasites by either prolonging the growth rate of the parasite (static compound) or by eradicating $T$. cruzi infection (cidal compound) in 72-96 h. A library screen of 920 FDA-approved drugs validated the HTS assay. Amongst these, we identified 65 FDA approved drugs that decreased amastigote proliferation by $\geq 75 \%$ and calculated their $\mathrm{EC}_{50}$ (JC Engel, unpublished observations). With the goal of rapidly identifying therapeutic compounds for Chagas disease, and to increase the throughput of the screening assay, we have now improved and automated the screen via use of a liquid handling robotic system. This automated HTS assay of amastigotes in host cells provides a powerful tool to screen drug libraries for trypanosomal hits and simultaneously assesses cytotoxicity to host cells.

\section{ACKNOWLEDGEMENTS}

To Sally Eccleston, for preparation of this manuscript.

\section{REFERENCES}

Andrade LO, Machado CR, Chiari E, Pena SD, Macedo AM 1999. Differential tissue distribution of diverse clones of Trypanosoma cruzi in infected mice. Mol Biochem Parasitol 100: 163-172.

Barr SC, Warner KL, Kornreic BG, Piscitelli J, Wolfe A, Benet L, McKerrow JH 2005. A cysteine protease inhibitor protects dogs from cardiac damage during infection by Trypanosoma cruzi. Antimicrob Agents Chemother 49: 5160-5161.

Brak K, Doyle PS, McKerrow JH, Ellman JA 2008. Identification of a new class of nonpeptidic inhibitors of cruzain. $J$ Am Chem Soc 130: 6404-6410.

Buckner FS, Joubert BM, Boyle SM, Eastman RT, Verlinde CL, Matsuda SP 2003. Cloning and analysis of Trypanosoma cruzi lanosterol 14alpha-demethylase. Mol Biochem Parasitol 132: 75-81.

Caffrey CR, Steverding D, Swenerton RK, Kelly B, Walshe D, Debnath A, Zhou YM, Doyle PS, Fafarman AT, Zorn JA, Land KM, 
Beauchene J, Schreiber K, Moll H, Ponte-Sucre A, Schirmeister T, Saravanamuthu A, Fairlamb AH, Cohen FE, McKerrow JH, Weisman JL, May BC 2007. Bis-acridines as lead antiparasitic agents: structure-activity analysis of a discrete compound library in vitro. Antimicrob Agents Chemother 51: 2164-2172.

Chen CK, Doyle PS, Yermalitskaya LV, Mackey ZB, Ang KKH, McKerrow JH, Podust LM 2009. Trypanosoma cruzi CYP51 inhibitor derived from a Mycobacterium tuberculosis screen hit. PLoS Negl Trop Dis 3: e372.

Chen YT, Lira R, Hansell E, McKerrow JH, Roush WR 2008. Synthesis of macrocyclic trypanosomal cysteine protease inhibitors. Bioorg Med Chem Lett 18: 5860-5863.

Coura JR, de Castro SL 2002. A critical review on Chagas disease chemotherapy. Mem Inst Oswaldo Cruz 97: 3-24.

de Andrade AL, Zicker F, de Oliveira RM, Almeida Silva S, Luquetti A, Travassos LR, Almeida IC, de Andrade SS, de Andrade JG, Martelli CM 1996. Randomised trial of efficacy of benznidazole in treatment of early Trypanosoma cruzi infection. Lancet 348: 1407-1413.

Delcroix M, Sajid M, Caffrey CR, Lim KC, Dvorak J, Hsieh I, Bahgat M, Dissous C, McKerrow JH 2006. A multienzyme network functions in intestinal protein digestion by a platyhelminth parasite. J Biol Chem 281: 39316-39329.

Doyle PS, Dvorak JA, Engel JC 1984. Trypanosoma cruzi: quantification and analysis of the infectivity of cloned stocks. J Protozool 31: $280-283$.

Doyle PS, Zhou YM, Engel JC, McKerrow JH 2007. Cysteine protease inhibitor cures Chagas disease in an immunodeficient-mouse model of infection. Antimicrob Agents Chemother 51: 3932-3939.

Du X, Guo C, Hansell E, Doyle PS, Caffrey CR, Holler TP, McKerrow JH, Cohen FE 2002. Synthesis and structure-activity relationship study of potent trypanocidal thio semicarbazone inhibitors of the trypanosomal cysteine protease cruzain. J Med Chem 45: 2695-2707.

Dvorak JA 1984. The natural heterogeneity of Trypanosoma cruzi: biological and medical implications. J Cell Biochem 24: 357-371.

Eddine AN, von Kries JP, Podust MV, Warrier T, Kaufmann SH, Podust LM 2008. X-ray structure of 4,4'-dihydroxybenzophenone mimicking sterol substrate in the active site of sterol 14alphademethylase (CYP51). J Biol Chem 283: 15152-15159.

Engel JC, Doyle PS, Dvorak JA 1985. Trypanosoma cruzi: biological characterization of clones derived from chronic chagasic patients. II. Quantitative analysis of the intracellular cycle. J Protozool 32: 80-83.

Engel JC, Doyle PS, Dvorak JA 1990. Isolate-dependent differences in the oxidative metabolism of Trypanosoma cruzi epimastigotes. Mol Biochem Parasitol 39: 69-76.

Engel JC, Doyle PS, Hsieh I, McKerrow JH 1998a. Cysteine protease inhibitors cure an experimental Trypanosoma cruzi infection. J Exp Med 188: 725-734.

Engel JC, Doyle PS, Palmer J, Hsieh I, Bainton DF, McKerrow JH 1998b. Growth arrest of T. cruzi by cysteine protease inhibitors is accompanied by alterations in Golgi complex and ER ultrastructure. J Cell Sci 111: 597-606.

Engel JC, Garcia CT, Hsieh I, Doyle PS, McKerrow JH 2000. Upregulation of the secretory pathway in cysteine protease inhibitorresistant Trypanosoma cruzi. J Cell Sci 113: 1345-1354.

Estani SS 1999. Treatment of Trypanosoma cruzi infection in the undetermined phase. Experience and guidelines of treatment in Argentina. Mem Inst Oswaldo Cruz 94 (Suppl. I): 363-365.
Fabbro DL, Streiger ML, Arias ED, Bizai ML, del Barco M, Amicone NA 2007. Trypanocide treatment among adults with chronic Chagas disease living in Santa Fe city (Argentina), over a mean follow-up of 21 years: parasitological, serological and clinical evolution. Rev Soc Bras Med Trop 40: 1-10.

Fricker SP, Mosi RM, Cameron BR, Baird I, Zhu Y, Anastassov V, Cox J, Doyle PS, Hansell E, Lau G, Langille J, Olsen M, Qin L, Skerlj R, Wong RS, Santucci Z, McKerrow JH 2008. Metal compounds for the treatment of parasitic diseases. J Inorg Biochem 102: 1839-1845.

Fujii N, Mallari JP, Hansell EJ, Mackey Z, Doyle P, Zhow YM, Gut J, Rosenthal PJ, McKerrow JH, Guy RK 2005. Discovery of potent thiosemicarbazone inhibitors of rhodesain and cruzain. Bioorg Med Chem Lett 15: 121-123.

Gallerano RR, Sosa RR 2000. Interventional study in the natural evolution of Chagas disease. Evaluation of specific antiparasitic treatment. Retrospective-prospective study of antiparasitic therapy. Rev Fac Cien Med Univ Nac Cordoba 57: 135-162.

Gauthier JY, Chauret N, Cromlish W, Desmarais S, Duong Ie T, Falgueyret JP, Kimmel DB, Lamontagne S, Leger S, LeRiche T, Li CS, Masse F, McKay DJ, Nicoll-Griffith DA, Oballa RM, Palmer JT, Percival MD, Riendeau D, Robichaud J, Rodan GA, Rodan SB, Seto C, Therien M, Truong VL, Venuti MC, Wesolowski G, Young RN, Zamboni R, Black WC 2008. The discovery of odanacatib (MK-0822), a selective inhibitor of cathepsin K. Bioorg Med Chem Lett 18: 923-928.

Greenbaum DC, Mackey Z, Hansell E, Doyle P, Gut J, Caffrey CR, Lehrman J, Rosenthal PJ, McKerrow JH, Chibale K 2004. Synthesis and structure-activity relationships of parasiticidal thiosemicarbazone cysteine protease inhibitors against Plasmodium falciparum, Trypanosoma brucei, and Trypanosoma cruzi. J Med Chem 47: 3212-3219.

Jaishankar P, Hansell E, Zhao DM, Doyle PS, McKerrow JH, Renslo AR 2008. Potency and selectivity of P2/P3-modified inhibitors of cysteine proteases from trypanosomes. Bioorg Med Chem Lett 18: 624-628.

Jannin J, Villa L 2007. An overview of Chagas disease treatment. Mem Inst Oswaldo Cruz 102 (Suppl. I): 95-97.

Kirchhoff LV, Engel JC, Dvorak JA, Sher A 1984. Strains and clones of Trypanosoma cruzi differ in their expression of a surface antigen identified by a monoclonal antibody. Mol Biochem Parasitol 11: $81-89$.

Lepesheva GI, Zaitseva NG, Nes WD, Zhow W, Arase M, Liu L, Hill GC, Waterman MR 2006. CYP51 from Trypanosoma cruzi: a phyla-specific residue in the B' helix defines substrate preferences of sterol 14alpha-demethylase. J Biol Chem 281: 35773585 .

McKerrow JH, Rosenthal PJ, Swenerton R, Doyle P 2008. Evelopment of protease inhibitors for protozoan infections. Curr Opin Infect Dis 21: 668-672.

Nozaki T, Dvorak JA 1993. Intraspecific diversity in the response of Trypanosoma cruzi to environmental stress. J Parasitol 79: 451-454.

Nozaki T, Engel JC, Dvorak JA 1996. Cellular and molecular biological analyses of nifurtimox resistance in Trypanosoma cruzi. Am J Trop Med Hyg 55: 111-117.

Podust LM, Poulos TL, Waterman MR 2001a. Crystal structure of cytochrome P450 14alpha-sterol demethylase (CYP51) from Mycobacterium tuberculosis in complex with azole inhibitors. Proc Natl Acad Sci USA 98: 3068-3073.

Podust LM, Stojan J, Poulos TL, Waterman MR 2001b. Substrate rec- 
ognition sites in 14alpha-sterol demethylase from comparative analysis of amino acid sequences and X-ray structure of Mycobacterium tuberculosis CYP51. J Inorg Biochem 87: 227-235.

Podust LM, von Kries JP, Eddine AN, Kim Y, Yermalitskaya LV, Kuehne R, Ouellet H, Warrier T, Altekoster M, Lee JS, Rademann J, Oschkinat H, Kaufmann SHE, Waterman MR 2007. Small-molecule scaffolds for CYP51 inhibitors identified by high-throughput screening and defined by X-ray crystallography. Antimicrob Agents Chemother 51: 3915-3923.

Podust LM, Yermalitskaya LV, Lepesheva GI, Podust VN, Dalmasso EA, Waterman MR 2004. Estriol bound and ligand-free structures of sterol 14alpha-demethylase. Structure 12: 1937-1945.

Postan M, Bailey JJ, Dvorak JA, McDaniel JP, Pottala EW 1987. Studies of Trypanosoma cruzi clones in inbred mice. III. Histopathological and electrocardiographical responses to chronic infection. Am J Trop Med Hyg 37: 541-549.

Postan M, McDaniel JP, Dvorak JA 1984. Studies of Trypanosoma cru$z i$ clones in inbred mice. II. Course of infection of C57BL/6 mice with single-cell-isolated stocks. Am J Trop Med Hyg 33: 236-238.

Ratier L, Urrutia M, Paris G, Zarebski L, Frasch AC, Goldbaum FA 2008. Relevance of the diversity among members of the Trypanosoma cruzi trans-sialidase family analyzed with camelids singledomain antibodies. PLOS ONE 3: e3524.

Renslo AR, McKerrow JH 2006. Drug discovery and development for neglected parasitic diseases. Nat Chem Biol 2: 701-710.

Rosenthal PJ, Sijwali PS, Singh A, Shenai BR 2002. Cysteine proteases of malaria parasites: targets for chemotherapy. Curr Pharm Des 8: 1659-1672.
Sosa Estani S, Segura EL, Ruiz AM, Velazquez E, Porcel BM, Yampotis C 1998. Efficacy of chemotherapy with benznidazole in children in the indeterminate phase of Chagas disease. Am J Trop Med Hyg 59: 526-529.

Souto-Padron T, Campetella OE, Cazzulo JJ, de Souza W 1990. Cysteine proteinase in Trypanosoma cruzi: immunocytochemical localization and involvement in parasite-host cell interaction. J Cell Sci 96: 485-490.

Streiger ML, del Barco ML, Fabbro DL, Arias ED, Amicone NA 2004. Longitudinal study and specific chemotherapy in children with chronic Chagas disease, residing in a low endemicity area of Argentina. Rev Soc Bras Med Trop 37: 365-375.

Tanowitz HB, Machado FS, Jelicks LA, Shirani J, de Carvalho AC, Spray DC, Factor SM, Kirchhoff LV, Weiss LM 2009. Perspectives on Trypanosoma cruzi-induced heart disease (Chagas disease). Prog Cardiovasc Dis 51: 524-539.

Tomás AM, Miles MA, Kelly JM 1997. Overexpression of crizipain, the major cysteine proteinase of Tripanosoma cruzi, is associated with enhanced metacyclogenesis. Eur J Biochem 224: 596-603.

Urbina JA 1999a. Chemotherapy of Chagas disease: the how and the why. J Mol Med 77: 332-338.

Urbina JA 1999b. Parasitological cure of Chagas disease: is it possible? Is it relevant? Mem Inst Oswaldo Cruz 94: 349-355.

Urbina JA 2001. Specific treatment of Chagas disease: current status and new developments. Curr Opin Infect Dis 14: 733-741.

Vieira M, Rohloff P, Luo S, Cunha-e-Silva NL, de Souza W, Docampo R 2005. Role for a P-type H+-ATPase in the acidification of the endocytic pathway of Trypanosoma cruzi. Biochem $J$ 392: 467-474. 